\title{
Regional Educational Performance Patterns in Europe
}

PÉTER RADÓ

$\approx$ The paper aims to contribute to the assessment of the contextual relevance of various educational policies through an analysis of three aspects of the performance profiles of European countries: participation, the quality of learning outcomes and the equity of learning outcomes. Comparative analysis of international student achievement assessment surveys and statistical data reveals three European performance patterns: the compensative education systems of North and Northwest Europe, the selective education systems of Central Europe and the attritional education systems of Southeast Europe. On the basis of the identified performance patterns, the paper provides a brief outline of major trends within the Central and Southeast European regions, shares reflections on the alignment of policies that fit the distinct context of the two regions and offers a conceptual framework for further comparative research.

Keywords: Central Europe, PISA, South Eastern Europe, Trends

\section{The historical regions of Europe}

Since no education system can be good or bad in comparison to itself, the only reliable way to assess the actual performance of the education of a country is international comparison. However, it happens too often that we compare the outcomes of our system with those of other countries with rather limited relevance. The further we go for international references, the greater the contextual differences that may reduce the validity of comparisons. Therefore, digging deeper into the contextual similarities and differences requires determining the group of countries that may serve as the basis of valid comparisons.

After the collapse of the Soviet Union, Eastern European communist systems and the former Yugoslavia, our approach to regional division within Europe remained very much determined by political categories. We often talked 
- and still talk - about the former communist countries and the countries of the former Yugoslavia where the "common heritage" determines all aspects of life, as well as the latitude for any development. However, all sorts of economic and social changes make this approach more and more dubious; in most aspects, Estonia appears to be more similar to Sweden than to Russia, and Slovenia is more similar to Austria than to Serbia. Gradually, the "historical regions of Europe" that - as the Hungarian historian Jenő Szücs demonstrated - developed their distinct characteristics through centuries of "structural changes" are reclaiming their explanatory power (Szücs, 1983).

Obviously, explaining social processes on the basis of common communist heritage is not a promising exercise anymore. Bulgaria and Romania are adjusting to the rest of the Southeast European region. Also, as the northern excommunist countries are applying Northern European type of institutions and the differences between Austria, the Czech Republic and Hungary are fading, Central Europe is recovering its shape. The reaggregation of the Southeast and Central European regions is very much visible in countries where the "borders" of the two larger European regions represent internal regional differences, such as in Croatia and Romania. (This shift in approach raises an extremely exciting question for international comparative research of education: how strong are these social and cultural determinations and to what extent do they constrain the latitude of public policies?) The question to be answered by the present paper is: are there regional patterns in education, too? If so, what are their major characteristics?

When the results of the 2000 PISA survey were published, the decline in the average performance of European countries along the North - Southeast axis was already visible. Ever since, in spite of sometimes even drastic positive or negative change in the performance of certain countries, the three regional performance groups have intractably survived: North and Northwest European countries with above OECD average performance (with which Poland had caught up by 2006), Central European countries below the OECD average and Southeast European countries well below the OECD average. Although the position of a few countries within their respective regional group has changed, the integrity of the performance groups abides. 


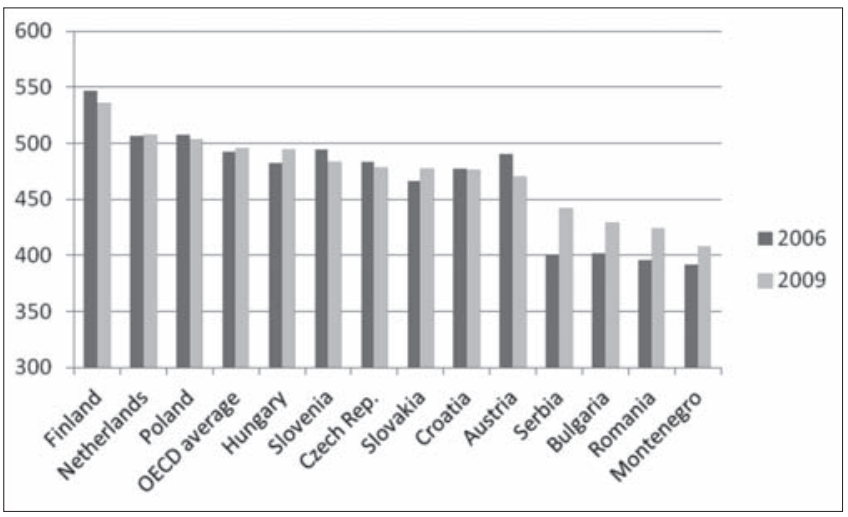

Figure 1: Average reading performance of students in selected European countries. (PISA 2006-2009) ${ }^{2}$

Still, to a certain extent these overall regional performance patterns can be explained by the different wealth of the various countries. As the report on the PISA 2009 results suggests, there is a relationship between the performance of education systems and the money spent on education (OECD, 2010). However, since we know that there is no direct causal relationship between inputs and learning outcomes, we need to dig deeper into the performance profiles of the education systems of Southeast and Central European countries.

\section{The composition of educational performance profiles}

The prevailing underlying concept of contemporary educational policies is based on a great emphasis on learning outcomes. The learning outcomes based approach is the result of two parallel processes: the growing emphasis on learning and learning pathways instead of emphasising teaching and school structure (lifelong learning), and the gradual reconsideration of relevant school knowledge, that is, the growing focus on applicable knowledge: the knowledge, skills and attitudes (competencies) that enable the learner to do things in diverse contexts (Radó, 2010/b). Due to this paradigm shift in education - and due to the increasing amount and quality of comparative student performance assessment information - we have a tendency to forget about the rather traditional statistical data and indicators. However, as the overview on the following

2 This and the following figures do not include all European countries. The selection of the countries for the figures is intended to illustrate regional patterns in a visible way; including all countries would not change the overall picture. 
pages will demonstrate, when judging the output of primary and secondary education systems we need to incorporate both types of information and should reveal how they are interlocked.

The performance profile of education systems is composed of three equally important aspects: (1) participation and progression, (2) the quality of learning outcomes and (3) the equity of learning outcomes. What determines the key features of an education system is the interplay between these aspects (Radó, 2010/a). In relation to any of these aspects there are many indicators available that enable comparative analysis. However, since the space in the present paper is limited, only certain signals will be offered that support the major conclusions and help to identify questions for further analysis and research. For the sake of simplicity and comparability, when outlining a brief overview of the quality and equity of learning outcomes the reading literacy results of the PISA survey will be used. (Incorporating PISA data on Mathematics and Science or the results of other international assessment surveys would not really change the overall picture.)

\section{Participation}

In spite of the sometimes questionable reliability of statistical data from Southeast Europe, it is obvious that there is a visible gap between the two European regions in terms of the key participation indicators. Dropout rates in primary education and enrolment rates in secondary education are much more favourable in Central Europe, the latter being almost universal. Participation in the countries of the Balkan Peninsula is especially dramatic for Roma children. For example, according to a 2005 UNDP survey, in Serbia the average duration of schooling of Roma children is 5.5 years, and only one Roma child completes primary education out of ten enrolled (UNDP, 2005). Although, as Figure 2 shows, there has been an improvement in secondary enrolment rates in most Southeast European countries in the last few years, around one fifth of students are still not in formal schooling when PISA measures the performance of 15-year-olds. Generally speaking, the most disadvantaged students are dropping out earlier in most of the countries of the region. Bulgaria is an exception, with participation figures closer to the Central European level and - at least according to the TransMonee database - Romania has also achieved a surprising improvement. 


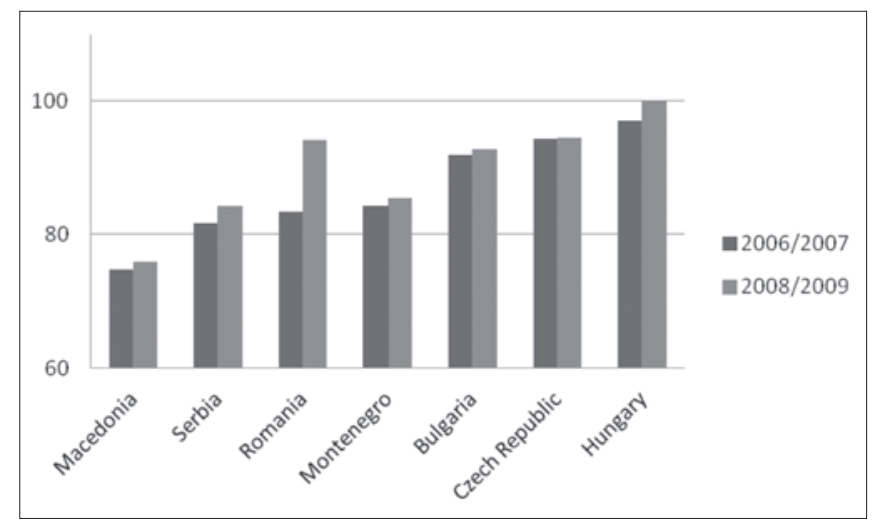

Figure 2: Upper-secondary education enrolment rates, 2006/07 and 2008/2009 school years. (percentage of population aged 15-18, ISCED 3, all programmes)

Source: TransMonee database

If we look at the proportion of early school leavers, which is the underlying indicator for one of the EU's 2020 benchmarks, it is rather salient that in this respect Central European countries are among the top performers on the continent. The relatively higher proportion of early school leavers in Austria and Hungary is the result of the high number of disadvantaged students dropping out from vocational training. Nevertheless, at the age of 15 the large majority of children are still attending schools in all Central European countries.

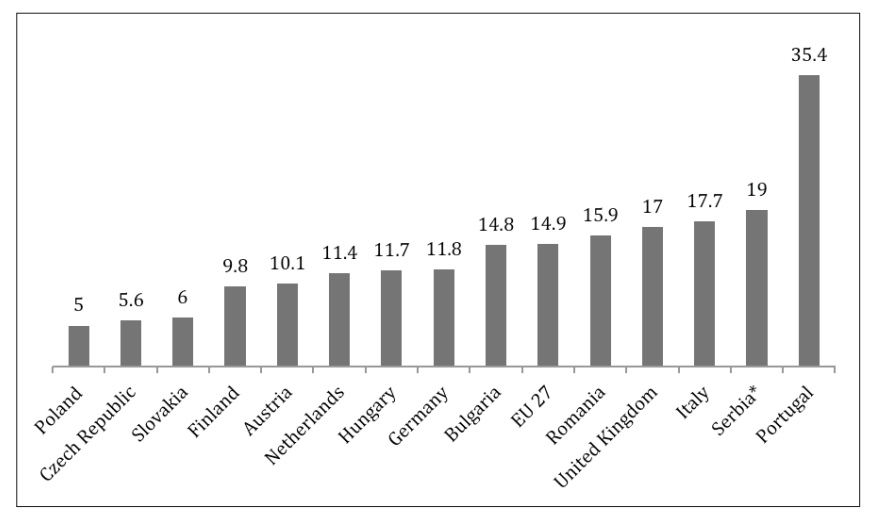

Figure 3: The proportion of the population aged between 18 and 24 years without completed upper secondary education and not undertaking education in selected European countries. (2009)

Source: EU Commission, 2009 ( ${ }^{\star}$ Serbia: estimate) 


\section{The quality of learning outcomes}

Data regarding the national average literacy results have already been presented in the introductory part of this paper. What is important to add here is the fact that national averages do not hide any serious deviations from the regional performance patterns highlighted earlier. For example, if we look at the proportion of extremely poorly performing (in fact, functionally illiterate) students we still see two clearly distinct groups: that of Central European countries below the OECD average and the group of Balkan countries with extremely high failure rates. (The only exception from the regional pattern is Hungary, which has fewer failing students.)

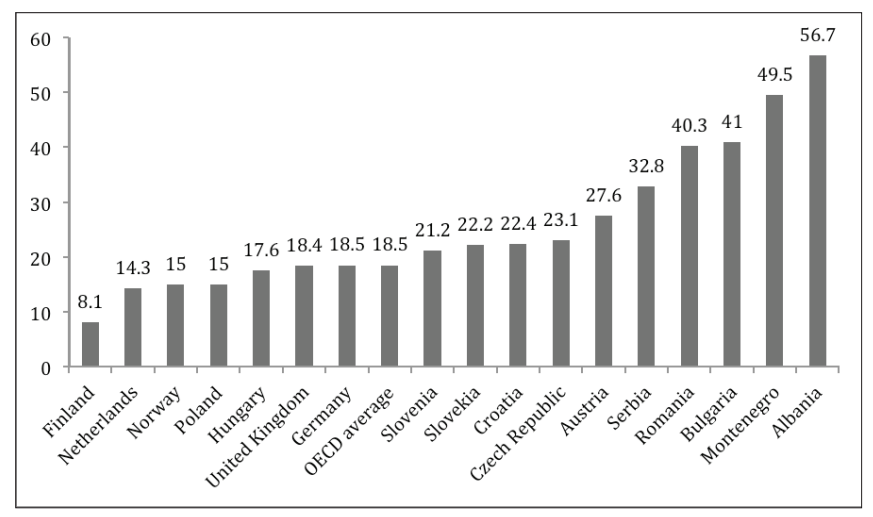

Figure 4: The proportion of students performing at level 1 or below in reading in selected European countries. (PISA 2009)

The other end of the performance scale within the different countries is even more instructive, because the most disadvantaged students did not participate in PISA in Southeast European countries and thus had less impact on the results. (Disadvantaged students are likely to perform more poorly.) In this comparison, the gap between the two regions is even wider and the performance of the countries belonging to the same region is more uniform. (In terms of the proportion of high performers, the exception is Bulgaria, which has results closer to the Central European level.) 


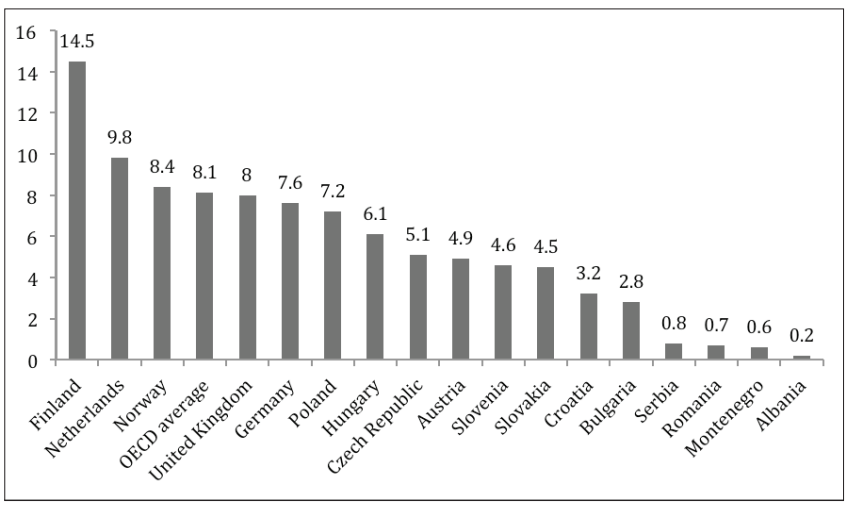

Figure 5: The proportion of students performing at level 5 or above in reading in selected European countries. (PISA 2009)

In order to have an even clearer view of the quality of learning outcomes in the countries of the two regions we can remove the impact of the background of the students. The economic, social and cultural background of the students is described by the ESCS index of PISA. Since the impact of the ESCS index on the performance of students is different in different countries, recalculating their average reading performances assuming a student background identical to that of the OECD average gives us a closer estimate of the quality of learning outcomes. The results of this calculation, shown in Figure 6, are striking: even minor performance differences between countries belonging to the two regions almost completely disappear, while the performance gap between the two regions remains significant. (Again, the exception is Hungary, whose calculated performance is higher than the level of the Central European region.) Of course, the performance of education systems is judged according to measured averages; in this respect this calculation is not particularly significant. Nevertheless, it is very much instrumental in demonstrating the strength of regional patterns of the quality of learning outcomes. 


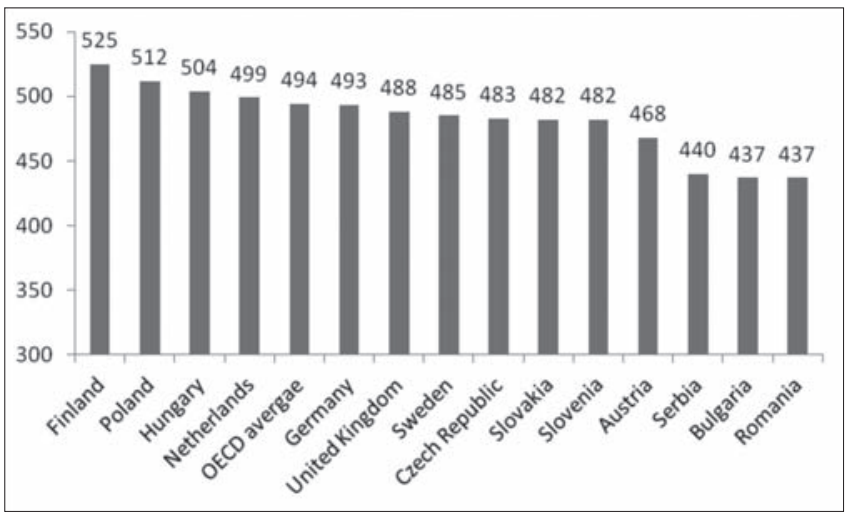

Figure 6: Calculated reading performance after removing the impact of different student backgrounds in selected European countries. (PISA 2009)

\section{Equity of learning outcomes}

When describing the equity of learning outcomes we need to turn to two basic characteristics of primary and secondary education systems: the strength of the aforementioned impact of student background on learning outcomes and the strength of selectivity within an education system.

As far as the impact of student background is concerned, the basic underlying question refers to the capacity of education systems to compensate for the negative impact of disadvantages on learning. This compensatory potential of education is high in countries where the impact of student background (in PISA: the ESCS index) generates lower score point differences, and low in countries where differences of background generate large achievement gaps. As the data of Figure 7 proves, schools in Austria, Hungary and the Czech Republic - and slightly less in Slovakia - are failing to compensate for disadvantages. According to many experts, in the case of Roma or immigrant children these education systems even intensify the detrimental impact of the background of students. The only European country that performs more poorly than the systems of Central European countries is Bulgaria. In contrast, on first sight it appears that Serbia, Montenegro and Romania are performing much better than countries of the neighbouring region. However, we should remember that the most "problematic" children have already dropped out of education by the time the PISA tests are administered. Therefore, among the countries selected in Figure 7 the only ones with a really high (i.e., above the OECD average) compensatory capacity are those of Northwest European: Finland, Norway and the Netherlands. 


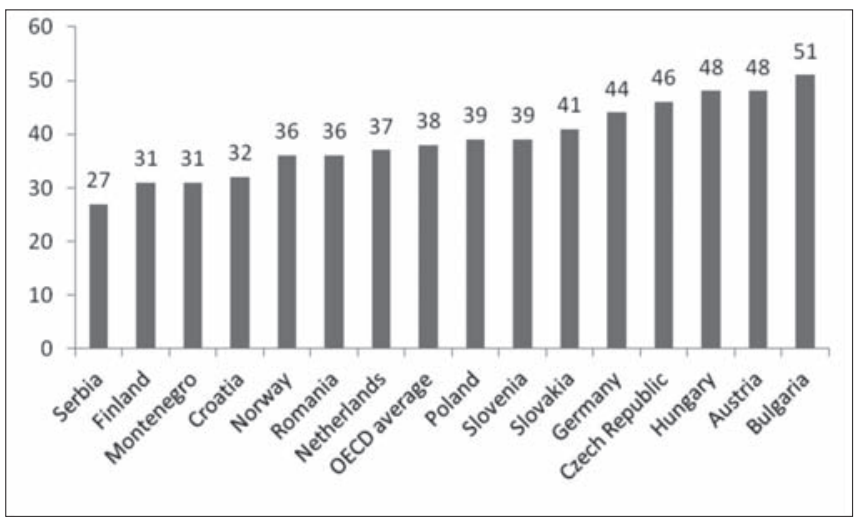

Figure 7: The impact of student background on learning outcomes (ESCS impact in score points) in selected European countries. (PISA 2009)

The other aspect of equity to be looked at is the extent to which these education systems are selective. In selective education systems there is strong pressure to separate all children who may cause difficulties in the teachinglearning process. As a result, in these systems there is a tendency to create homogeneous classrooms for both advantaged and disadvantaged students. As various analyses have shown, average achievement levels are significantly higher in heterogeneous classrooms than in homogeneous classrooms. Therefore, selection reduces the average performance of those children who are separated or segregated.

The intensity of selection is indicated by the extent to which the variance of achievement results is explained by differences between schools and within schools. If differences between schools prevail in an education system, the system is selective. As the comparison of selectivity of education shown in Figure 8 demonstrates, the regional pattern of Central Europe is not so salient, despite the fact that the education systems of the region are the most selective systems in Europe; the extent to which differences between schools explain the variance of student performance is much higher than the OECD average in all of these countries. The extreme selectivity of education in Hungary is even more striking if we recall that while the age when children are sorted into different tracks of the school system is 10-11 years in Austria, the Netherlands and Germany, in Hungary this only occurs at the age of 14-15 years for the large majority of students. On first sight, the regional pattern of the Balkans disappears here; however, we again need to be aware of the large number of disadvantaged students missing from the PISA sample. 


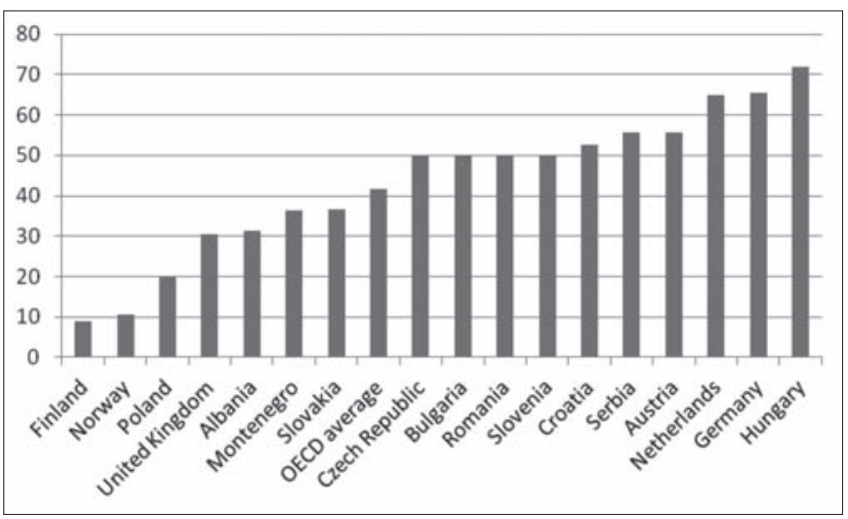

Figure 8: Selectivity of education systems (the proportion of variance explained by differences between schools) in selected European countries. (PISA 2009)

\section{Regional performance patterns}

After reviewing some indicators regarding the three aspects that compose the performance profile of the primary and secondary education systems, we can assume with a high probability that there are distinct regional performance patterns. Moreover, we may attempt to summarise the key characteristics of the three regional patterns that will allow us to assess changes within individual countries against their respective regional references.

\section{Characteristics of the three regional performance patterns}

On the basis of the reviewed participation, quality and equity indicators, as well as on the basis of the interplay between them, we can identify three performance patterns along the Northwest - Southeast axis of Europe. These patterns are: (1) the compensative education systems of North and Northwest European countries, (2) the selective education systems of Central European countries, and (3) the attritional education systems of the Southeast European region (Radó, 2010/a). The key characteristics of the three patterns are the following:

- Compensative education systems:

- Almost universal secondary completion

- Above OECD average quality of learning outcomes

- High level of equity (low impact of background, weak selection) 
- Selective education systems:

- Almost universal secondary completion

- Below OECD average quality of learning outcomes

- Low level of equity of learning outcomes (high impact of background and very strong selection)

- $\quad$ Attritional education systems:

- High dropout in primary education

- Relatively poor quality of learning outcomes

- Average equity at secondary level

In short, the relative inability of schools in Central European countries to compensate for the impact of various disadvantages - combined with relatively high quality and high participation - results in very strong selectivity, that is, the streaming of students with different backgrounds into different tracks of education. The country where the education system represents the most extreme version of the Central European pattern is Hungary. On the one hand, after removing the impact of student background, the quality of learning outcomes in Hungary is significantly higher, while, on the other hand, schools are unable to compensate for disadvantages and the level of selection is extremely high. Since inequities impose greater downward pressure on the performance of the system in Hungary than in any of the other Central European countries, the average PISA results are not significantly higher than in the other countries of the region.

In comparison to Central European countries, the lower quality and weaker compensatory capacity in Southeast European countries leads to very high primary education dropout, especially among the most vulnerable student groups, such as the Roma. The example of Bulgaria, which in many respects sticks out from the regional pattern, is very instructive. Bulgaria is more successful in terms of enrolling and retaining children in formal schooling, but the quality of education at the age when PISA measures the competencies of students is no different from other countries in its own region. Therefore, the impact of student background on learning outcomes is the highest in all of Europe. As the 2006 PIRLS results suggest, the relative success of Bulgaria regarding participation is not independent of the fact that the quality of the first years of education is higher than in the rest of the Balkan region (PIRLS, 2006.)

Thus, we have two distinct regional patterns with rather specific performance profiles. As a consequence, the real reference for the countries of Central and Southeastern Europe is the countries of their own respective regions. 


\section{A closer look at Central Europe}

Although the Central European performance pattern was maintained in all of the four consecutive PISA surveys, there was a remarkable redistribution of positions within the region. In the former top performer countries (Austria and the Czech Republic), the reading competencies of students declined throughout the entire decade (the decline in the Czech Republic was more persistent, but the decline in Austria was more dramatic). In contrast, reading competencies improved in Hungary and Slovakia to a significant extent (the improvement in Hungary is comparable to that in Poland, which is Europe's development champion.)

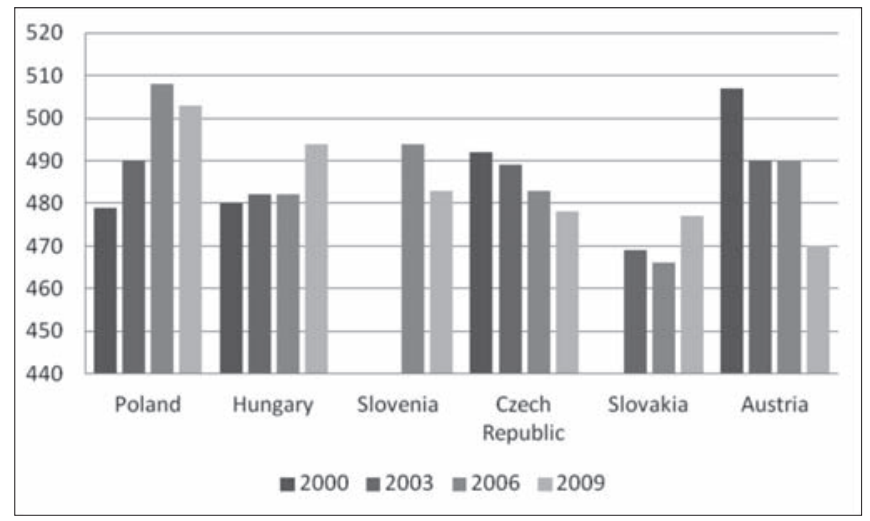

Figure 9: Average reading performance of students in Central European countries. (PISA 2000-2009)

If we look at the reasons for the advance or decline of reading competencies it is quite obvious that both changes - just like in Poland - are the result of a change in the proportion of underperforming students (the change in the proportion of high performing students was much smaller than that of failing students). 


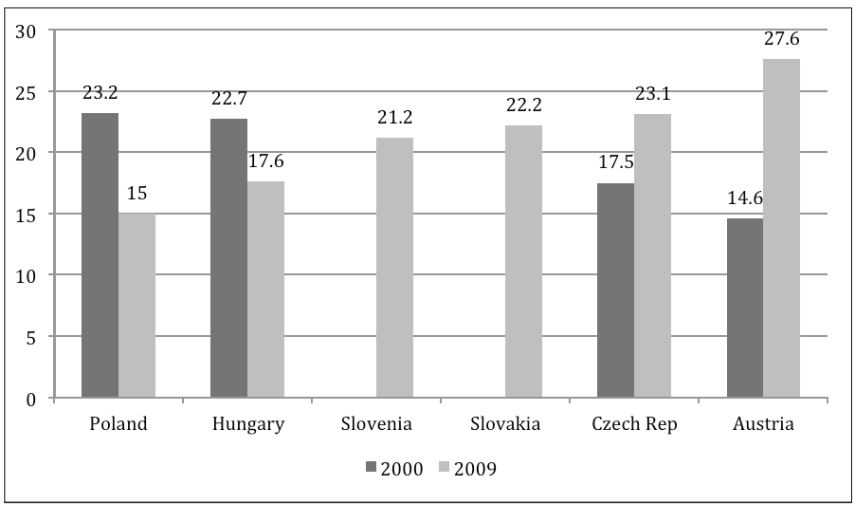

Figure 10: The proportion of students performing at level 1 or below level 1 in reading in Central European countries. (PISA 2000-2009)

At the same time, the significant change in the quality of learning outcomes did not result in significant changes in terms of equity. Therefore, the basic feature of the performance profile of Central European education systems remained the same: a gap between quality and equity.

\section{A closer look at Southeast Europe}

In contrast to Central Europe, the originally rather homogeneous performance level of the Southeast European region - especially between the 2006 and 2009 PISA surveys - has become more diverse. The growing difference between these countries is generated by their different levels of success in increasing the reading performance of students. In comparison to the rest of Europe, the advance achieved by Serbia, Romania, Bulgaria and Montenegro is tremendous. However, we can predicate the results of further research and evaluation by saying that improving results from a rather low basis is much easier than any even moderate improvement at a much higher performance level. For example, according to Serbian experts, sending reading tests to schools for practice led to great improvement in itself. Therefore, we may assume that, to a certain extent, one of the side effects of assessment - "test result inflation" (i.e., teaching to the test) - also contributed to the better results. 


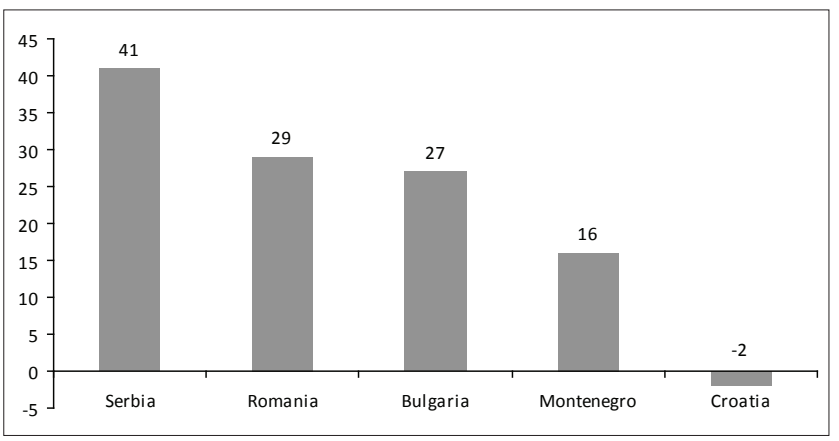

Figure 11: Change in the average reading performance of students in Southeast European countries. (PISA 2006-2009)

As in Central Europe, the major factor behind the change in overall performance in PISA was the decline of the proportion of failing students (in 2006, every second 15-year-old child was functionally illiterate in Serbia, Romania and Bulgaria). Again, the proportion of students with outstanding reading competencies basically remained the same.

\begin{tabular}{|c|ccc|}
\hline Serbia & Romania & Bulgaria & Montenegro \\
\hline \hline & & & \\
\hline \\
\hline
\end{tabular}

Figure 12: Change in the proportion of students performing at level 1 or below level 1 in reading in Southeast European countries. (PISA 2006-2009)

Certain trends in the Southeast European region clearly prove the validity of the above described performance pattern. For example, as mentioned earlier, in the period between the 2006 and 2009 PISA surveys, secondary enrolment was improved in all of the Balkan countries. The improvement in the capacity of the education system immediately resulted in greater selectivity in almost all of the countries of the region. This suggests that - according to the 
Bulgarian pattern - if nothing else changes, better participation indicators automatically change equity indicators for the worse. There are two exceptions. The first is Romania, where there are doubts about the reliability of the incredible improvement in the participation-related EU indicator (these doubts are supported by the unchanged selectivity of the Romanian system). The other example of Bulgaria, where in the last years of the previous decade - before the introduction of decentralised per capita financing - a large scale school system rationalisation programme was implemented, with the closure of many hundreds of schools. The removal of surplus capacities from the system inevitably led to much weaker selectivity.

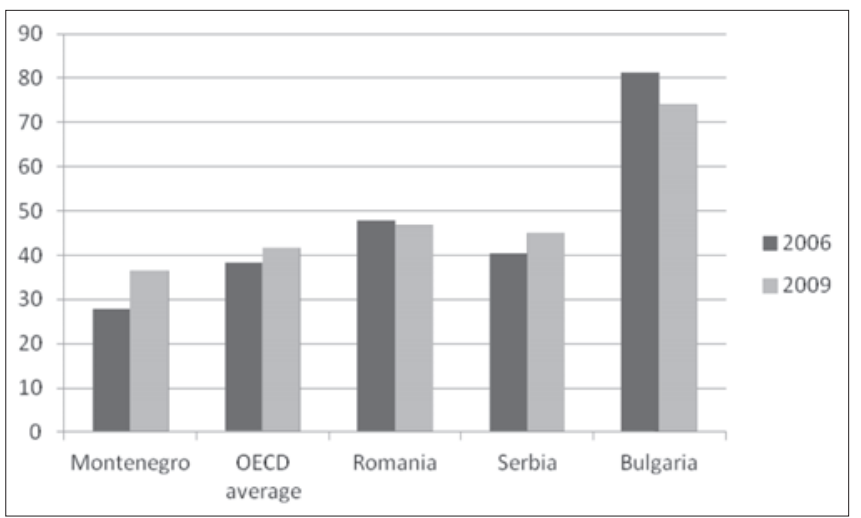

Figure 13: Selectivity: change in the proportion of variance of results explained by differences between schools in Southeast European countries. (PISA 2006-2009)

\section{Policy implications}

The policy implications of the above outlined analysis are tremendous. All policies should target the very specific problems of an education system. In other words: the contextual relevance of policies is essential. When governments consider the improvement of the overall performance of their education systems, looking at good policy practices that have proved to be effective in improving average competence results somewhere else is far from being sufficient. As may be obvious already, ameliorating literacy or any other competence level requires addressing the very specific problems of the performance profile of an education system. No doubt, this calls for rather different policy approaches in Southeast and Central Europe.

As far as the specific Central European context is concerned, the policy 
dilemmas of countries with declining performance and with improving performance need to be raised in a different way. However, the common foundation for educational policies in the region lies in the fact that the underlying problems are much more related to equity than to the quality of learning outcomes. Strengthening the capacity of schools to compensate for disadvantages and reducing selection within the school system are the key objectives that educational policies should focus on. For justification, the Hungarian example is quite enlightening; the heavy investment in the development of primary and secondary education between 2002 and 2008 resulted in an upgrading of quality indicators, but the gravity of serious equity-related problems remained the same.

For these purposes, it is worth looking at the skeleton of education reform in Poland at the end of the nineties, which moved the performance profile of Polish education closer to the top performing European countries in less than a decade. The Polish reform combined two basic components: (1) a school structure reform by introducing a new comprehensive school type for grades 7-9, and (2) strengthening professional accountability by introducing a performance standard-based school leaving examination at all of the three exit points (Jakubowski et al., 2008). The reason for regarding this policy model as applicable is the fact that it addresses the entire (mainstream) system, instead of focusing on supplementary targeted measures for specific student groups. (Operating with supplementary measures only is an approach that has proved to be ineffective in all Central European countries.)

A variation of this type of reform may well contribute to the improvement of the educational performance of Central European countries through improved equity of learning outcomes. Of course, there are no policy solutions that can be easily transferred from one country to another. A comparative analysis of the equity policies of Central European countries has revealed that - in spite of the very similar performance pattern of these countries - there are extreme differences in the systemic environment of education (Radó, 2009). Therefore, the "Polish reform model" needs serious adjustments to the specific context of each country.

The policy challenge in Southeast European countries is rather different and much more complex. So far, we have seen that improving enrolment without improving the quality of teaching and schools inevitably leads to worsening the equity of learning outcomes. Therefore, governments need to consider how to address all of the three components of the performance profile of their education. Bearing in mind the rather limited policy planning and implementation capacity of governments in Southeast European countries, intervention of this scope and scale appears to be a mission impossible. What might be more 
feasible is a sequential policy approach with two phases. In the medium term, a "back to basics" policy seems to be appropriate: strong emphasis on ensuring universal primary completion and secondary enrolment, as well as on strengthening the learning foundations during the elementary phase of schooling. At a certain point, a gradual shift might occur towards policies that address growing equity problems, which will be very similar to the recent problems of Central European countries (Radó, 2010/a).

In relation to policy planning, the difficulties in Southeast Europe are much more serious, also due to the fact that all of the countries of this region operate highly centralised governance and management systems, while Central European countries have already undergone an almost complete decentralisation process. One of the most striking features of centralised governance systems is that they do not offer a favourable environment for the implementation of policies of any kind. (The systemic environment of schools is much less diverse in Southeast Europe than in the neighbouring region - highly centralised systems are much more alike than the decentralised systems.)

\section{Towards a deeper understanding of regional patterns}

Obviously, the brief comparative analysis presented on these pages only scrapes the surface of the extremely complex characteristics of the education systems of the two regions. The reasons for the similarities between the countries belonging to the same regional patterns are still invisible, and revealing them requires a great deal of further research. However, there are no doubts about the added value of comparative studies, both in terms of understanding problems and of informing policy making.

The assumption that there are distinct educational performance patterns is already very much instrumental for formulating the underlying questions for further research. The research efforts of the future should aim to provide more insight into policies that may work within a specific context. The path to these insights starts with gaining a better understanding of the mechanisms that cause these similarities. Figure 14 offers a conceptual framework for systematic comparative studies. It includes three relevant layers of problems: comparative analysis (1) of the way schools operate (teaching and the organisational work of schools), (2) of the systemic environment of schools, that is, the interplay between the various functional governance instruments, and (3) of those economic, social, demographic and technological processes that have an impact on governance and schools. 


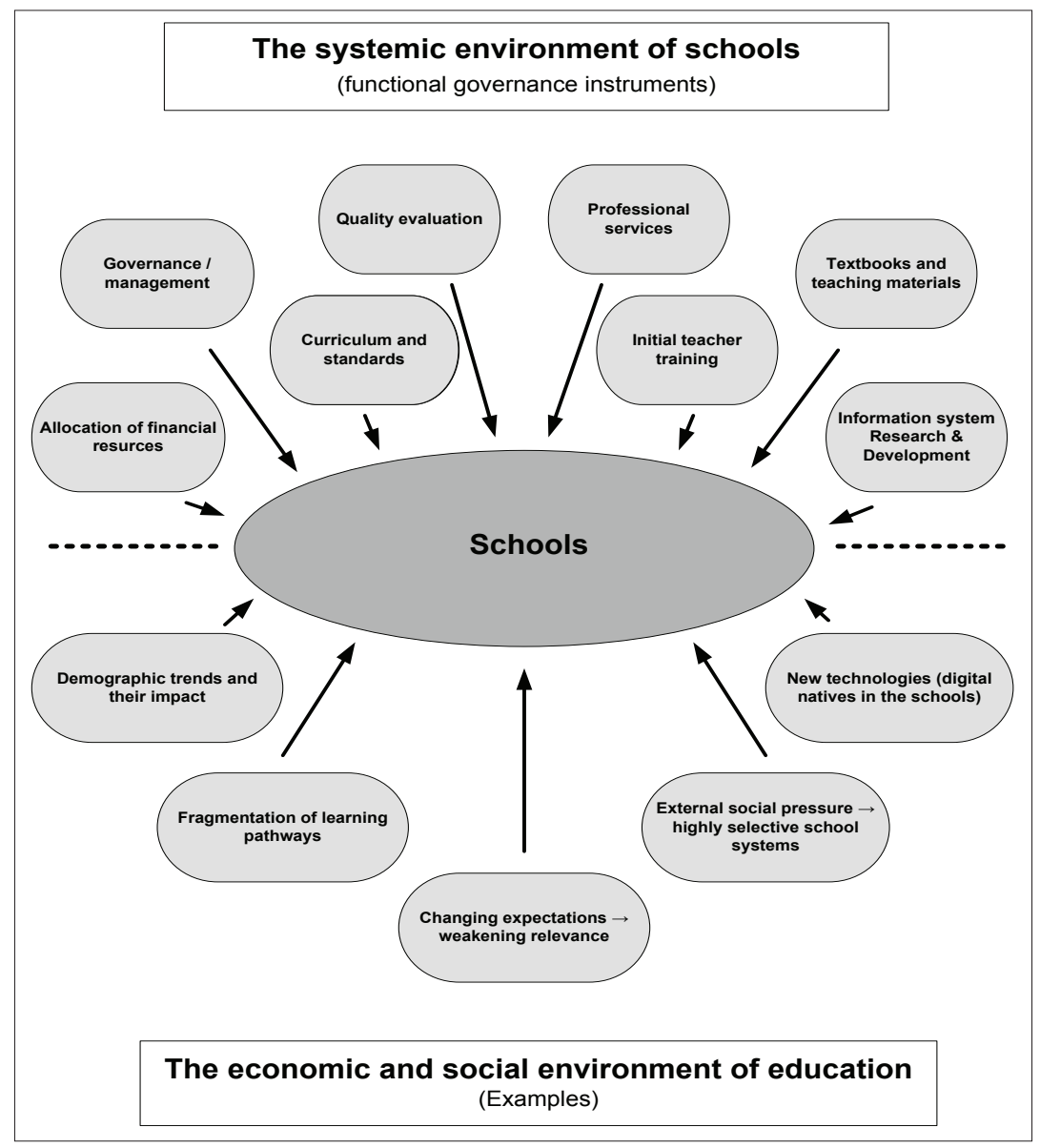

Figure 14: A framework for regional comparative analysis.

The international comparative information that served as the raw material of this overview leads us into the trap of learning of any kind: the more we know, the more we are aware of other things that we do not know. 


\section{References}

CEDEFOP (2008). The Shift to Learning Outcomes. Conceptual, Political and Practical Developments in Europe.

EU Commission (2009). Progress Towards the Lisbon Objectives in Education and Training. Indicators and Benchmarks 2009. Commission staff working document Jakubowski, M., Patrinos, H. A., Porta, E. E., \& Wisniewski, J. (2008). The Impact of the 1999 Education Reform in Poland. Retreived from http://www.eale.nl/Conference2009/Programme/ PapersC/add102407_pjtWNKQqMQ.pdf. OECD (2010). PISA 2009 Results: What Makes a School Successful? Resources, Policies and Practices.

(Volume IV).

PIRLS 2006. International Report. IEAs Progress in International Reading Literacy Study in Primary Schools in 40 Countries (2007). IEA.

Radó, P. (2009). Equity in Education - Synthesis Report: The Potential and Limitations of the Learning Outcomes Based Approach. Policy-Making for Equity in Education in Austria, the Czech Republic, Hungary, Slovakia and Slovenia. In Equity in Education. Country Notes of a Central European Project. Tempus Public Foundation 2009.

Radó, P. (2010/a). School Failure in Serbia. Psiholoska Istrazivanja, XIII(1).

Radó, P. (2010/b). Governing Decentralized Education Systems. Systemic Change in South Eastern Europe. Local Government and Public Service Reform Initiative. Budapest: Open Society Institute. Szűcs, J. (1983). Vázlat Európa három történeti régiójáról. Gyorsuló idő. Budapest: Magvető Kiadó. TransMONEE database. Monitoring the Situation of Women and Children in Central and Eastern Europe and the Commonwealth of Independent States. Retreived form http://www.transmonee.org/. UNDP (2005). Vulnerable Groups in Central and Southeastern Europe. 


\section{Biographical note}

PÉTER RADó is an expert in educational policy analysis and evaluation. From 1998 he has been working as the Assistant Director of the Institute for Educational Policy in the Open Society Institute, Budapest. Between 2003 and 2007 he was the director of the Center for Educational Policy Analysis in Hungary. Currently he divides his time between teaching at various university programs and working as a consultant in Central-eastern Europe and in South Eastern Europe. He has contributed to a number of technical assistance programs, participated in several capacity building programs and evaluation programs at a European scale. He has also published more than 60 studies and books in various European languages. 